\title{
“NUDGE” NO MANEJO DOS RESÍDUOS DOMICILIARES COMO PREMISSA PARA A RESPONSABILIDADE SOCIOAMBIENTAL
}

\author{
"NUDGE" IN THE MANAGEMENT OF DOMICILIARY WASTE AS PREMISE \\ FOR SOCIAL AND ENVIRONMENTAL RESPONSIBILITY
}

\author{
Carlos Morais Vila-Nova ${ }^{1}$ \\ Henrique Ribeiro Cardoso ${ }^{2}$ \\ Fernando Gustavo Knoerr ${ }^{3}$
}

\section{RESUMO}

O lixo, embora com reconhecido potencial econômico em razão da ampla perspectiva de reutilização e de reciclagem, caso mal acondicionado ou destinado, polui a atmosfera, o solo e as águas, gerando vários danos ambientais à preservação do planeta e consequentemente às espécies vivas. Nesse passo, o artigo tem como focos o esclarecimento das mazelas geradas pelo manejo inadequado do lixo a partir dos domicílios brasileiros e a reflexão sobre a existência de soluções pautadas na economia comportamental. O problema de pesquisa consiste em se a aplicação da economia comportamental, nudge, pode ser uma ferramenta para aprimorar o manejo dos resíduos. Inicialmente, destaca-se a relevância da matéria, que decorre das degradações à natureza causadas pelo próprio ser humano, que através de suas ações provoca catástrofes em várias localidades da terra. Após, aborda-se sobre como a questão dos resíduos perpassa pela conduta nos lares brasileiros, que é substancialmente relevante para minorar os impactos ambientais e atenuar o grave problema social dos catadores, constituindo-se, assim, como uma prática salutar; e como podem ser aplicados os nudges nesse cenário. O método científico utilizado corresponde à abordagem dialética,

\footnotetext{
${ }^{1}$ Mestrando em Direitos Humanos pela Universidade Tiradentes. Especialista em Direito Civil e Processual pela Universidade Tiradentes (2012), Professor da Universidade Tiradentes. Advogado.

${ }^{2}$ Doutor em Direito, Estado e Cidadania (UGF/Rio), com Pós-doutorado em Democracia e Direitos Humanos (IGC - Universidade de Coimbra) e Pós-doutorado em Direitos Humanos e Desenvolvimento (PPGCJ/UFPB); Mestre em Direito, Estado e Cidadania (UGF/Rio); Especialista em Direito Constitucional Processual (FAPESE/UFS); Graduado em Direito pela Universidade Estadual de Santa Cruz (UESC/Bahia); Professor do Programa de Pós-graduação da Universidade Federal de Sergipe (Mestrado/PRODIR/UFS); Professor de Programa de Pós-graduação da Universidade Tiradentes (Mestrado/PPGD/UNIT); Professor da Escola Superior do Ministério Público de Sergipe (ESMP/SE); Membro da Academia Sergipana de Letras Jurídicas (ASLJ/SE); Promotor de Justiça em Sergipe.

${ }^{3}$ Doutor em Direito do Estado pela Universidade Federal do Paraná (2002). Mestre em Direito do Estado pela Universidade Federal do Paraná (1998). Bacharel em Direito pela Universidade Federal do Paraná (1993). Ex-Procurador Federal. Professor de Direito Administrativo da Escola da Magistratura do Paraná e da Fundação Escola do Ministério Público do Paraná / FEMPAR. É Professor Permanente do Programa de Mestrado em Direito Empresarial e Cidadania do UNICURITIBA. Realizou estágio Pós- Doutoral na Universidade de Coimbra, Portugal (2015-2016).
} 
comparando as ideias e argumentações de publicações na internet e livros de direito ambiental, mediante pesquisa bibliográfica e documental. Conclui-se que os nudges podem ser instrumentos de modificação dos costumes danosos ao meio ambiente, e então, que sua aplicação no manejo dos resíduos domiciliares é benéfica ao mesmo.

Palavras-chave: Ambiente. Conscientização. Domicílio. Responsabilidade.

\begin{abstract}
Garbage, although the economic potential is known because of the broad perspective of reuse and recycling; if ill-conditioned or destined pollutes atmosphere, soil and water, generating various environmental damages to the preservation of the planet and consequently to living species. In this step, the article focuses on the ills generated by the inadequate management of waste from Brazilian households and the reflection on the existence of solutions based on behavioral economics. The research problem is whether the application of behavioral economics, nudge, can be a tool to improve waste management. Initially, the relevance of the matter is highlighted, which results from the degradations to nature caused by the human being himself, who through his actions causes catastrophes in various localities of the earth. Afterwards, it is approached about how the waste issue pervades conduct in Brazilian households, which is substantially relevant to reduce environmental impacts and alleviate the serious social problem of waste pickers, thus constituting a salutary practice; and how the nudges can be applied in this scenario. The scientific method used corresponds to the dialectical approach, comparing the ideas and arguments of publications on the internet and environmental law books, through bibliographical and documentary research. It is concluded that the nudges can be instruments of modification of the habits harmful to the environment, and therefore, that their application in the management of the household residues is beneficial to the same
\end{abstract}

Keywords: Awareness. Environment. Residence. Responsibility.

\title{
INTRODUÇÃO
}

A problemática dos resíduos constitui-se num tema que apresenta relevância e enseja pesquisa e análise, face aos problemas ambientais e de saúde decorrentes do acondicionamento e destinação inadequada do lixo - termo este utilizado de forma depreciativa. Os resíduos domésticos possuem potencial econômico significativo, tendo em vista a ampla perspectiva de reutilização e de reciclagem desses materiais.

Diante do desequilíbrio ambiental e do déficit na preservação dos recursos naturais, o cenário ambiental, de maneira geral, não é favorável no Brasil. Isso porque existem lixões espalhados, catadores em condições laborais sub-humanas, o que é constatado com frequência na maioria das cidades brasileiras, salvo exemplos minoritários que adotam boas práticas.

Esse estudo, então, tem como objetivo promover uma reflexão, investigando sobre os resíduos domiciliares e o manejo dispensado pelos indivíduos em seus lares. Destarte, no desenvolvimento deste trabalho, verifica-se que tem crescido no Brasil os níveis de 
consciência ambiental. Entretanto, o grande paradoxo desse crescimento é o fato recalcitrante do brasileiro não coletar, nem separar, nem acondicionar e nem destinar de forma adequada os resíduos das suas próprias casas, apartamentos ou condomínios.

$\mathrm{Na}$ pesquisa, faz-se referência à palavra inglesa propagada no meio acadêmico, denominada "nudge", que teve grande projeção após o lançamento do livro Nudge - O Empurrão para a Escolha Certa, dos escritores americanos Cass Sunstein e Richard Thaler, traduzido para o idioma português no ano de 2009.

Portanto, com base no significado do termo inglês de cutucar ou induzir positivamente, encontra-se inspiração para investigar esse tema inquietante e apresentar uma visão geral com esclarecimentos e argumentos condizentes para uma mudança comportamental a partir dos domicílios brasileiros.

Através desse significado, questiona-se se o uso da economia comportamental pode auxiliar na proteção do meio ambiente, especificamente, quando à questão do "lixo". Nesse contexto, a hipótese de pesquisa é que a utilização de nudges relacionados ao manejo do lixo doméstico pode representar um turning point significativo no tocante à proteção ambiental no Brasil.

O método utilizado na pesquisa, que é bibliográfica e documental, foi o método de abordagem dialética, comparando as ideias e argumentações de publicações, livros de direito ambiental e legislação, mediante pesquisas descritivas e explicativas. Logo, a pesquisa também é bibliográfica e documental.

Desse modo, no sentido de aperfeiçoar a exposição do tema, o artigo foi dividido em quatro capítulos, da seguinte forma: o primeiro sobre o contexto brasileiro, o segundo com a aclaração a respeito do subtema Responsabilidade Socioambiental, seguido pelos comentários à Lei dos Resíduos Sólidos e por fim as reflexões sobre Educação e Conscientização a partir dos Lares para as Mudanças Estruturais.

\section{RESÍDUOS DOMICILIARES E CRISE AMBIENTAL: O PANORAMA BRASILEIRO}

O estudo da temática afigura-se como um dos principais trilhos para a consciência ambiental e proteção da biodiversidade. O lixo urbano é um embrulho que atinge o mundo 
inteiro, tendo em vista o crescimento exagerado do consumo e pelas formas desorganizadas de logísticas.

Pesquisas do Senado Federal apontam que o Brasil está entre os dez maiores produtores de resíduos no mundo ao lado de países como China, Índia e México, sendo o ranking liderado pelos norte-americanos. Entretanto, neste país, as boas práticas de tratamento e destinação desses materiais estão distantes dos padrões satisfatórios, considerando a forma de gestão dos países de vanguarda, mesmo diante de questões tão propagadas mundialmente como o desequilíbrio ambiental e a preservação dos recursos naturais.

Apesar de centros com boas práticas, como ocorre em algumas capitais do Brasil, o panorama ainda é de lixões espalhados, que promovem condições sub-humanas de geração de rendas para os denominados catadores de lixos, cujos ambientes insalubres de trabalho apresentam-se como alternativas para a obtenção de sustento e sobrevivência. Nesses locais, só há espaço para trânsito de caçambas e caminhões empanturrados de resíduos e atmosfera intolerável, face ao apodrecimento dos produtos jogados (MUCELIN; BELLINI, 2008, p. 115-117).

Consoante informado no Jornal Nacional (2017), as pessoas são amontoadas sobre dejetos e sem proteção nos diversos lixões espalhados pelo país, sob péssimas condições; fato este que ocorre com maior incidência em regiões menos desenvolvidas, como no CentroOeste e Nordeste do Brasil. Todavia, a situação é extensiva a todo país, ocorrendo, por exemplo, em outras localidades como a Baixada Fluminense no Estado do Rio de Janeiro, que tem uma extensa área coberta de lixo e entulho próxima a Baía de Guanabara; e como no Estado de São Paulo -cuja maioria do lixo vai para o lugar certo- que tem 14 mil toneladas de resíduos descartados em lixões diariamente.

Hodiernamente, com essa geração consumerista indiscriminada que só aumenta e sem mecanismos adequados de gestão, junto à sociedade, no sentido de promover um destino racional dos resíduos; a questão redunda num problema ambiental (RESENDE, 2015, p. 2729). "Percebe-se, portanto, que o consumo é essencial para a sobrevivência do ser humano. Entretanto os padrões atuais de utilização dos recursos naturais prejudicam imensamente a natureza, contribuindo para a degradação ambiental” (GIDDENS, 2012, p. 144-145).

Face aos graves problemas sociais que historicamente perduram no Brasil, como desemprego, desamparo aos direitos sociais mais elementares, segurança e distribuição de renda, a existência dos "lixões" estendidos pelos recantos nacionais constitui-se como uma 
fonte de renda para milhares de famílias que vivem à margem da pobreza, sofrendo as mais primárias privações (MUCELIN; BELLINI, 2008, p. 112-123).

Nesse toar, de forma simplificada, reciclagem é o reaproveitamento de materiais descartados dos lares, da indústria e de outros inúmeros estabelecimentos, mediante a utilização destes como matéria-prima para novos produtos.

Além da reciclagem dos denominados resíduos sólidos para o reaproveitamento na indústria; existe, também, a técnica da compostagem que transforma e acelera a decomposição de restos orgânicos de alimentos, trapos de roupas, serragens, entre muitos outros, transformando-os em fertilizantes e fontes de energia.

\section{RESPONSABILIDADE SOCIOAMBIENTAL E PROTEÇÃO LEGAL DO MEIO AMBIENTE}

A temática em pauta sobre os resíduos provenientes do consumo humano, da indústria, formas de condução e reciclagem, catadores, apresenta conotação social, ambiental e econômica. Contudo, o trabalho em desenvolvimento se atém a questão social de indignidade dos citados catadores, assim como, a temática do ambientalismo, tão difundida e protagonizada.

No campo da legalidade, pelos ditames da Carta Maior (BRASIL, 1988), dispõe o artigo $3^{\circ}$, I que constitui objetivo fundamental da República Federativa do Brasil "construir uma sociedade livre, justa e solidária".

Depreende-se que a responsabilidade de construir essa sociedade, justa e solidária não é só do Estado. Desse modo, deve consolidar-se pela contribuição individual de cada cidadão, por intermédio do senso de pertencimento e de compromisso com os graves problemas sociais existentes no país, tal qual, a dos catadores de lixo.

Para a questão, com a inspiração na Carta Magna, cabe citar Carlos Augusto Machado (2015) que menciona no seu artigo "Constitucionalismo Fraternal”, a moldura jurídicoconstitucional do Estado brasileiro comprometido com a fraternidade entre o seu povo. Comprometimento este que não deve ser só do Estado, mas de toda a sociedade.

Nesse toar, o autor Carlos Machado assevera que:

Com o compromisso preambular, todos os brasileiros - numa perspectiva particularmente jurídica, Estado, governo, povo e segmentos organizados da 
sociedade civil, passaram a ser, individual e conjuntamente, responsáveis não somente pela construção de uma sociedade voltada à formação de nacionais ou, mesmo, cidadãos, mas uma sociedade de irmãos. Uma sociedade fraterna (iguais em dignidade, irmãos em essência). Não se contentou o legislador constituinte em apresentar as bases de uma sociedade politicamente organizada e juridicamente institucionalizada (2015, p. 11).

As carências das condições mínimas existenciais penalizam substancialmente grande parte dos brasileiros, como os catadores de lixo, redundando em consequências nefastas para a própria sociedade, além de comprometer a qualidade do Estado Democrático, meio a significativa parcela da população limitada por necessidades biológicas.

Frente a isso, os graves problemas sociais que assolam o país podem ser minimizados com ações coletivas e individuais que promovam o Constitucionalismo Fraternal elencado na Carta Magna e retratado por Machado (2015) - ações essas que podem ser maximizadas nos diversos rincões do país.

Atualmente não se podem dissociar os aspectos sociais das questões ambientais porque o próprio homem faz parte dessa natureza e dela necessita para sobreviver. Conforme Silva, Adolfo e Carvalho (2015, p. 15):

Existe, portanto, uma reciprocidade de responsabilidade em relação a questões ambientais e de proteção da dignidade da pessoa, incumbindo tanto ao estado quanto aos indivíduos da sociedade. Tudo isso como maneira de alcançar os direitos humanos visto que um dano causado ao meio ambiente resultará num prejuízo aos direitos fundamentais da vida com dignidade, saúde e bem-estar.

O tema sobre meio ambiente ganhou relevância a partir de publicações, debates e conferências; inicialmente, provindas de países hegemônicos. Posteriormente, propagou-se por todo o mundo como um alarme. A emergência deveu-se às evidências de degradações ambientais, que provocaram e provocam desequilíbrios na natureza, causando catástrofes em várias localidades, consoante as notícias que chegam das diversas partes do globo terrestre. Além do mais, a poluição atmosférica que provoca graves problemas de saúde à população. Desse modo, cuidar do meio ambiente passou a ser um assunto de sobrevivência para as gerações do presente e do futuro (CUSTODIO; VIEIRA, 2015, p. 161) ${ }^{3}$.

\footnotetext{
${ }^{3}$ Afinal, como pontua Beck (2003, p. 206): "Nosso mundo é a sociedade de risco. É preciso compreendê-lo como uma realidade que atingiu um nível de ameaça muitíssimo superior à nossa imaginação".
} 
No Brasil, ocorrências como o acidente radioativo com o césio-137, o vazamento de óleo na Bahia de Guanabara e por último o rompimento da barragem de Mariana/MG em 2015 foram acidentes geradores de danos ambientais de grandes proporções,

Face à gravidade da questão, ouve-se e lê-se de forma recorrente sobre a necessidade de ambiente sustentável, que só se equilibrará através comportamentos e ações da sociedade de forma comprometida com a problemática da proteção ao meio ambiente; tratando-o de maneira ponderada e responsável para a manutenção do ecossistema em condições favoráveis na atualidade e para as gerações vindouras.

Sobre o tema sustentabilidade relacionado ao meio ambiente:

Mundialmente a palavra sustentabilidade começou a ser propagada a partir da realização da Conferência das Nações Unidas sobre o Meio Ambiente Humano - United Nations Conference on the Human Environment (UNCHE), em junho de 1972, em Estocolmo. A partir deste evento, que foi o primeiro encontro mundial promovido com o objetivo de discutir assuntos relacionados ao meio ambiente e soluções para a preservação da humanidade, o conceito de sustentabilidade passou a ganhar uma maior importância. No Brasil, a expressão "sustentabilidade", ganhou dimensões maiores após a realização da Conferência sobre Meio Ambiente e Desenvolvimento (ECO), em 1992, no Rio de Janeiro (TEMPOS DE GESTÃO).

No campo da sustentabilidade, a atividade humana no cotidiano passou a ser referência em relação à ameaça de elevação da temperatura atmosférica, poluição dos rios e mares, o aquecimento global face a emissão de elevadas quantidade de gases, sobretudo, os dióxidos de carbonos, que apresentam grau de absorção significativa pela atmosfera.

“Mas o que seria a responsabilidade ambiental?", questiona Sirvinskas (2013) sobre a responsabilidade civil e penal por dano causado por disposição inadequada de resíduos sólidos, e reflete que:

A responsabilidade civil por dano causado por disposição irregular de resíduos sólidos é objetiva. Assim, sem prejuízo da obrigação de, independentemente da existência de culpa, reparar os danos causados, a ação ou omissão das pessoas físicas ou jurídicas que importe inobservância aos preceitos desta lei, em especial às fixadas na Lei n. 9.605 de 12 de Fevereiro de 1998, "que dispõe sobre as sanções penais e administrativas derivadas de condutas e atividades lesivas ao meio ambiente, e dá outra providências" e em seu regulamento (art. 51 da Lei n. 12.305/2010). (SIRVINSKAS, 2013, p.270).

$\mathrm{Na}$ esfera do direito penal, segundo Granziera: 
Cabe ao Poder Judiciário estabelecer as penas restritivas que melhor se aplicam a cada caso concreto, devendo considerar, para isso, o disposto no art. $6^{\circ}$ da Lei de Crimes Ambientais, que fixa os seguintes critérios: "(1) a gravidade do fato, tendo em vista os motivos da infração e suas consequências para a saúde pública e o meio ambiente; (2) os antecedentes do infrator quanto ao cumprimento da legislação de interesse ambiental e (3) a situação econômica do infrator, no caso de multa", como aqueles fixados no art. 59 do Código Penal: (1) culpabilidade, (2) antecedentes, (3) conduta social, (4) personalidade do agente, (5) motivos, (6) circunstâncias e consequências do crime. (GRANZIERA, 2015, p.785)

No campo domiciliar, atenção especial deve ser dada a Lei 12.305 de 02 de agosto de 2010 (BRASIL), no tocante às ações individuais e familiares, tendo em vista que a responsabilidade ambiental se materializa nos lares, principalmente, pela separação dos resíduos sólidos recicláveis dos materiais orgânicos e acondicionamento destes para a destinação adequada. Ademais, mostra-se primordial coibir práticas como despejar óleo de cozinha no sistema de esgotos e consumos excessivos de água e energia elétrica.

A Lei 12.305/2010 (BRASIL) instituiu a Política Nacional de Resíduos Sólidos e apresenta nos seus cinquenta e sete artigos um arcabouço normativo para a condução e gestão dos resíduos sólidos que podem ser reutilizados na cadeia produtiva da indústria, além de tratar dos rejeitos sólidos, consoante o artigo $3^{\circ}, \mathrm{XV}$ da legislação.

Isto posto, sobre esses materiais inaproveitáveis, alude a lei sobre a acomodação destes de forma ambientalmente adequada, depois de esgotadas todas as possibilidades de tratamento e recuperação por processos tecnológicos De forma inaugural, o artigo $1^{\circ}$ da Lei 12.305 (2010, BRASIL) aduz:

Art $1^{\circ}$. Esta Lei institui a Política Nacional de Resíduos Sólidos, dispondo sobre seus princípios, objetivos e instrumentos, bem como sobre as diretrizes relativas à gestão integrada e ao gerenciamento de resíduos sólidos, incluídos os perigosos, às responsabilidades dos geradores e do poder público e aos instrumentos econômicos aplicáveis.

$\S 1^{\text {o }}$ Estão sujeitas à observância desta Lei as pessoas físicas ou jurídicas, de direito público ou privado, responsáveis, direta ou indiretamente, pela geração de resíduos sólidos e as que desenvolvam ações relacionadas à gestão integrada ou ao gerenciamento de resíduos sólidos.

$\S 2^{\circ}$ Esta Lei não se aplica aos rejeitos radioativos, que são regulados por legislação específica.

Todavia, sobre a lei, cabe ressaltar o histórico do seu processo legislativo, diante da problemática nacional, conforme Marcelo Abelha Rodrigues (2016): 
Explica-se a demora pelo fato de que o Projeto de Lei passou por internos debates e muita luta contra lobbies econômicos. Afinal, a presente lei enfrentou problemas (e venceu alguns deles) de grande interesse econômico, como alteração de matrizes energéticas na produção de bens de consumo, responsabilização dos geradores de resíduos (empresas), educação do consumidor e alteração dos padrões de consumo, entre outros aspectos igualmente importantes. (RODRIGUES, 2016, p. 198).

Consoante exposto, houve um atraso significativo na instituição da referida Lei. Entretanto, mesmo transcorridos tantos anos, ela continua representando uma conquista para as causas ambientais brasileiras, com a previsão de coleta seletiva de resíduos sólidos. Ainda mais, com as orientações de reutilização dos resíduos por meio da reciclagem, compostagem e aproveitamento enérgico, que visam evitar danos à saúde pública e a minimização dos impactos ao meio ambiente.

Depreende-se da lei 12.305 (BRASIL, 2010) o amparo do meio ambiente pelo princípio da responsabilidade compartilhada pelo ciclo de vida dos produtos, envolvendo além poder público, fabricantes, importadores e distribuidores. Nessa mesma esteira, leva-se em consideração a importância do princípio da cooperação entre os poderes públicos da administração direta e particulares para a consecução dos objetivos de gestão integrada do ambientalmente correto.

Infere-se no campo dos objetivos sobre o incentivo à indústria de reciclagem, capacitação técnica, mediante a gestão integrada dos entes públicos e de toda a sociedade. Ainda, anuncia a integração dos denominados catadores de "lixo", envolvendo-os numa responsabilidade compartilhada pelo ciclo de vida dos produtos (BRASIL, 2010).

Quanto aos instrumentos, o texto legal incentiva a criação de cooperativas voltadas à associação dos catadores de materiais reutilizáveis e recicláveis, segmento indispensável à rotulagem ambiental. Ainda, estimula a cooperação técnica entre os setores atuantes, assim como, o sistema de logística reversa e outras ferramentas relacionadas à implementação da responsabilidade compartilhada pelo ciclo de vida dos produtos (BRASIL, 2010).

A citada logística reversa proporciona benefícios mutuamente satisfatórios, tendo em vista que as empresas podem auferir vantagens financeiras ao diminuir o seu custo de produção com os produtos reutilizados ou reciclados. No contexto social, ganha toda a população, face à redução do acúmulo de resíduos. 


\section{NUDGES NOS LARES COMO FERRAMENTAS PARA AS MUDANÇAS ESTRUTURAIS}

Para ilustrar a dimensão da atual consciência e responsabilização ambiental no Brasil, cita-se Oliveira (2014), que se utilizou de dados do Instituto Brasileiro de Geografia e Estatística (IBGE):

A pesquisa de informações básicas municipais (munic 2013), divulgada pelo IBGE constatou que noventa por cento dos municípios brasileiros dispunham de algum órgão para tratar do meio ambiente em 2013, representando um aumento de 5,5 pontos percentuais em relação a 2009, período em que $84,5 \%$ das cidades dispunham de órgãos ambientais. Em relação a 2002, o índice foi de $67,8 \%$ dos municípios com órgãos voltados exclusivamente para questões ambientais, no entanto, este crescimento chega a 22,2 pontos percentuais (OLIVEIRA, 2014).

A pesquisa acima, ainda, apresenta uma peculiaridade, aduzindo que em termos relativos, a existência de estrutura administrativa cresce à medida que se avança os municípios menos populosos: 82,3\% com até 5 mil habitantes têm órgãos voltados para o meio ambiente; percentual que sobe para $97,4 \%$ entre aqueles com mais de 500 mil habitantes (OLIVEIRA, 2014).

Em matéria publicada em 12/03/2018 sobre a quantidade de lixo produzido no Brasil e a respeito do percentual reciclado, impende transcrever:

Para se ter ideia da gravidade desta situação, dados divulgados pela Associação Brasileira de Empresas de Limpeza Pública e Resíduos Especiais (ABRELPE) apontam que a quantidade de lixo produzido no Brasil vem batendo recorde ano após ano. Em 2015, foram geradas 79,9 milhões de toneladas de lixo em todo país, número 1,7\% maior do que gerado em 2014 (FRAGMAQ).

Sobre o percentual de reciclagem, a matéria retro citada apresenta o seguinte teor:

De acordo com dados do Plano Nacional de Resíduos Sólidos (PNRS), apesar de $30 \%$ de todo lixo produzido no Brasil ter potencial de reciclagem, apenas $3 \%$ de fato é reaproveitado. Esses números revelam que há um grande desperdício tanto do ponto de vista ambiental quanto econômico e social, uma vez que a reciclagem é uma fonte de renda para milhares de famílias (FRAGMAQ, 2018).

Nesse contexto, os ambientes insalubres dos lixões, lotados de resíduos e dejetos com odores fortes ao olfato humano são locais de trabalho, inclusive de crianças e adolescentes 
que atuam por si só ou em assessoramento aos familiares. O estudo em voga com enfoque nos resíduos domiciliares, como premissa basilar para a efetiva consciência e responsabilização ambiental de cada brasileiro, tem cunho propositivo para melhoria comportamental e atingimento de parâmetros aceitáveis, ou seja, compatíveis com as melhores práticas mundiais.

Como uma das soluções para a problemática, estuda-se o conceito de Nudge: desenvolvido por Richard Thaler e Cass Sunstein, que o definem como algo semelhante a um empurrão, uma indução que é realizada em função de uma pessoa e de seus comportamentos em sociedade, motivando e induzindo de forma sutil para escolhas racionais; mas, sem interferir nas liberdades (THALER; SUNSTEIN, 2009, p. 4)

Em matéria publicada na internet, Daniela Barbará (2017) se posiciona na forma a seguir:

Até pouco tempo o termo Nudge não tinha muito significado na minha vida. Afinal parecia mais um termo de economês que definiria uma tendência moderna. Mas isso tem mudado depois da publicação do livro do Cass Sunstein e Richard Thaler sobre o tema. O que é? Nudge é um neologismo que significa empurrãozinho, ou seja, nós podemos usar esses conhecimentos que temos sobre a cognição humana sobre a tomada de decisão pra ajudar as pessoas a agirem, a se portarem de uma maneira mais positiva para elas próprias e em termos coletivos também (BARBARÁ, 2017).

Nesse toar, parte-se do "nudge", ou seja, cutucando sutilmente às pessoas para se portarem de forma mais positiva e benéfica. Entretanto, meio ao cotidiano frenético que exige uma atuação intensa e multifuncional de cada indivíduo, necessário a indicação de condutas simplificadas e pragmáticas.

Outra questão fundamental permeia o descarte do óleo de cozinha na pia ou diretamente no esgoto, de forma inadequada, que termina contaminando o solo, rios e mares. A título de esclarecimento, impende transcrever enunciado de publicação informativa da Ecycle:

Após utilizar o óleo de fritura velho (de preferência em pouca quantidade), você pode armazená-lo em uma garrafa PET. Utilize um funil para facilitar a entrada do óleo na garrafa. Conforme for utilizando o óleo, vá armazenando desse modo e lembre-se de sempre fechar bem as garrafas para evitar vazamentos, mantendo também fora do alcance de crianças e animais de estimação que podem ser atraídos pelo cheiro do óleo ou pela simples curiosidade. Após preencher algumas garrafas PETs, procure empresas e ONGs especializadas neste tipo de coleta seletiva, assim como postos de 
entrega voluntária para descartar o seu óleo de forma correta (ECYCLE, 2018).

Tratando-se da causa ambiental, a problemática do lixo depende da mudança comportamental maximizada a partir dos lares brasileiros. Desse modo, a Lei 12.305/2010 deve atuar como um guia à adoção de melhores práticas que contribuam de fato para a proteção e preservação do ecossistema, mediante o incremento da reciclagem e reaproveitamento dos resíduos, assim como, melhoria nos níveis de dignidade e respeito ao labor dos milhares de catadores, que poderiam ser condecorados com uma nova denominação de separadores de resíduos.

Mas não somente, os nudges podem ser utilizados para melhorar esse manejo. Sendo eles fundados em pesquisas empíricas das ciências comportamentais, como psicologia comportamental e economia comportamental, eles podem auxiliary significativamente na mudança de comportamento dos poluidores (EVANS et al., 2017, p. 4 ).

Kollmuss e Agyeman (2002, p. 240) entendem como comportamento pró- meio ambiente aqueles que são direcionados a minimizar danos e impactos negativos das ações humanas, como a diminuição do uso de substâncias tóxicas, por exemplo.

Em outro nível, o Estatal, podem-se ser taxadas ou penalizadas as empresas mais poluidoras, favorecidas as menos poluidoras e induzida a adoção de outras estratégias para mudar os comportamentos e minorar os danos ao meio ambiente (THALER; SUNSTEIN, 2008, p. 186).

Nesse sentido, "os gestores públicos têm o desafio de incorporar a Economia Comportamental no ciclo das políticas e transformar esse desafio em oportunidades para gerar intervenções governamentais mais efetivas e eficientes" (MENEGUIN; ÁVILA, 2015, p.212).

\section{CONSIDERAÇÕES FINAIS}

O tema ambientalismo tem sido propagado pelo mundo, face às catástrofes ocasionadas pelos desequilíbrios no ecossistema. Nesse toar, o comportamento humano no cotidiano passou a ser referência em relação à poluição, aquecimento global e extinção de espécies vivas da fauna e flora.

Desse modo, a problemática do lixo que cresce indiscriminadamente, face ao agigantamento do consumo, tem se constituído como uma das principais mazelas ao meio ambiente. 
Para a questão, voltando-se ao Brasil, atenção especial deve ser dispensada à Lei 12.305/2010, no tocante às ações familiares de separação dos resíduos sólidos recicláveis, contribuindo para uma questão social relevante dos denominados catadores de lixos. Estes são tratados de forma aviltante, apesar da relevante contribuição que atenua a degradação da biodiversidade.

O objetivo do trabalho, inspirado no conceito de "nudge", que tem sido propagado nos ambientes de pesquisas acadêmicas, é cutucar o leitor para uma reflexão sobre o seu comportamento domiciliar em relação ao manejo dos resíduos.

Por fim, conclui-se sobre a importância da mudança comportamental para minimizar os danos socioambientais comprovados e gerados por negligências das tarefas mais simples e elementares, como executar ou delegar o manejo adequado dos resíduos na própria residência. Ademais, resta clara a indicação de que os nudges podem ser importantes aliados da preservação do meio ambiente.

No campo do pragmatismo que a problemática requer, a alternativa indicada apresenta-se básica e factível através do uso da economia comportamental. Nesse ponto, a pesquisa é concluída com a confirmação da hipótese levantada.

\section{REFERÊNCIAS}

BARBARÁ, Daniela. Opinião: “O Nudge, o Elefante e a Economia Comportamental”. $2017 . \quad$ Disponível em: <http://portalimprensa.com.br/noticias/opiniao/79981/opiniao+o+nudge+o+elefante+e+a+eco nomia+comportamental+por+daniela+barbara>. Acesso em: 17 dez. 2018.

BECK, Ulrich. Liberdade ou Capitalismo: Ulrich Beck conversa com Johannes Willms. Tradução: Luiz Antônio Oliveira de Araújo. São Paulo: Ed. Unesp, 2003.

BRASIL. Constituição da República Federativa do Brasil. Brasília, DF, 1988: Senado Federal. Disponível em: < http://www.planalto.gov.br/ccivil_03/constituicao/constituicao24.htm>. Acesso em: 30 de outubro, 2017.

BRASIL. Lei 12.305, de 2 de agosto de 2010. Disponível em: <http://www.planalto.gov.br/ccivil_03/_Ato2007-2010/2010/Lei/L12305.htm _. Acesso em: 17 dez. 2018.

CUSTODIO, M. M.; VIEIRA, E. G. O desenvolvimento sustentável à luz do direito fundamental ao meio ambiente ecologicamente equilibrado. Meritum: revista de direito da Universidade FUMEC, Faculdade de Ciências Humanas, Sociais e da Saúde, Belo Horizonte, v. 10, n. 1, p. 159-197, 
jan./jun 2015. Disponível em: <http://seer.ufrgs.br/index.php/ppgdir/article/view/51610/31918>. Acesso em: 12. jul.2018.

ECYCLE. Descarte de Óleo de Cozinha: Como Fazer. Disponível em: $<$ https://www.ecycle.com.br/2293-descarte-de-oleo-de-cozinha $\geq$. Acesso em: 20 dez. 2018. FRAGMAQ. Descubra a Quantidade de Lixo Produzido no Brasil e a Porcentagem do que é Reciclado. Disponível em: < https://www.fragmaq.com.br/blog/descubra-quantidadede-lixo-produzido-no-brasil-e-porcentagem-do-que-e-reciclado/>. Acesso em: 17 dez. 2018.

EVANS, Nicholas; EICKERS, Stephanie; GEENE, Leonie; TODOROVIC, Marijana; VILLMOW, Annika. Green Nudging: A discussion and preliminary evaluation of nudging as an environmental policy instrument. Centro de pesquisa de política ambiental -Universidade Livre de Berlim. Berlim. 2017. Disponível em: <

https://www.researchgate.net/publication/318394998_Green_Nudging_A_discussion_and_preliminary _evaluation_of_nudging_as_an_environmental_policy_instrument>. Acesso em: 15. dez. 2018.

GIDDENS, Anthony. Sociologia. Tradução: Ronaldo Cataldo Costa; revisão técnica: Fernando Coutinho Cotanda. 6. ed. Porto Alegre: Penso, 2012.

GRANZIERA, Maria Luiza Machado. Direito Ambiental. 4. ed. São Paulo: Atlas, 2015.

JORNAL NACIONAL. Brasil tem quase 3 mil Lixões ou Aterros Irregulares, diz Levantamento, 08 de maio de 2017. Disponível em: <http://g1.globo.com/jornalnacional/noticia/2017/05/brasil-tem-quase-3-mil-lixoes-ou-aterros-irregulares-dizlevantamento.html>. Acesso em: $17 \mathrm{dez} .2017$.

KOLLMUSS, Anja; AGYEMAN, Julian. Mind the Gap: why do people act environmentally and what are the barriers to pro-environmental behavior?. Environmental Education Research, Vol. 8, No. 3, 2002. Disponível em:

<https://www.researchgate.net/publication/235363126_Mind_the_Gap_Why_Do_People_Act_Enviro nmentally_and_What_Are_the_Barriers_to_Pro-Environmental_Behavior>. Acesso em: 28. dez. 2018.

MACHADO, Carlos Augusto Alcântara. Constitucionalismo Fraternal. Revista Diálogos Possíveis, Salvador, ano 14, número 2, p. 3-19, jul./dez. 2015. Disponível em: $<$ http://revistas.faculdadesocial.edu.br/index.php/dialogospossiveis/article/view/307/241>.Ac esso em 17 dez. 2018.

MENEGUIN, Fernando B.; ÁVILA, Flávia. A Economia Comportamental aplicada a Políticas Públicas. Em: ÁVILA, Flávia; BIANCHI, Ana Maria. Guia de Economia Comportamental e Experimental. Tradução: Laura Teixeira Motta - $1^{\text {a }}$ ed. - São Paulo: EconomiaComportamental.org, 2015. Disponível em: www.economiacomportamental.org/guia-economia-comportamental.pdf $>$. Acesso em: 19. dez. 2018. p. 210-220 
MUCELIN, Carlos Alberto; BELLINI, Marta. Lixo E Impactos Ambientais Perceptíveis No Ecossistema Urbano. Sociedade \& Natureza, Uberlândia, 20 (1): 111-124, jun. 2008. Disponível em: <http://www.scielo.br/pdf/sn/v20n1/a08v20n1〉. Acesso em: 27. jan. 2018.

OLIVEIRA, Nielmar. Pesquisa do IBGE Informa que 90\% do Municípios tem Órgão Ambiental. Disponível em: <http://agenciabrasil.ebc.com.br/geral/noticia/2014-04/ibge-90dos-municipios-tem-orgao-ambiental>. Acesso em: 17 dez. 2018.

RESENDE, Augusto César Leite de. A tutela jurisdicional do direito humano ao meio ambiente sadio perante a corte interamericana de direitos humanos. 1. ed Belo Horizonte: Editora Fórum, 2015.

RODRIGUES, Marcelo Abelha. Direito Ambiental Esquematizado. 3. ed. São Paulo: Saraiva, 2016.

SENADO FEDERAL. Aumento da Produção de Lixo tem Custo Ambiental. Disponível em: <https://www12.senado.leg.br/emdiscussao/edicoes/residuos-solidos/mundo-rumo-a-4bilhoes-de-toneladas-por-ano $\geq$. Acesso em: 17 dez. 2018.

SILVA, D. F.; ADOLFO, L. G. S.; CARVALHO, S. A. Direitos Humanos, Desenvolvimento Sustentável e Sustentabilidade. Revista Eletrônica do Curso de Direito da UFSM, Santa Maria, v. 10, n. 1, p. 1-24, 2015. Disponível em: < https://periodicos.ufsm.br/revistadireito/article/view/15383>. Acesso em: 14. jul. 2018.

SIRVINSKAS, Luís Paulo. Manual de Direito Ambiental. 11. ed. São Paulo: Saraiva, 2013.

THALER, Richard H.; SUNSTEIN, Cass R. Nudge : improving decisions about health, wealth, and happiness. New Haven \& London: Yale University Press. 2008

THALER, Richard H; SUNSTEIN, Cass R, Nudge: O Empurrão para a Escolha Certa. Tradução de Marcello Lino. Rio de Janeiro: Elsevier, 2009.

TEMPOS DE GESTÃO. Conceito de... Sustentabilidade. Disponível: <https://www.temposdegestao.com/conceito-de/conceito-de-sustentabilidade>. Acesso em: 17 dez.2018. 